\title{
São Luís: cidade portuária em transformação
}

São Luís: a changing port city

\author{
José Clementino \\ Graduado em Administração, Mestre em Transport and Maritime Economics
}

\begin{abstract}
Resumo Portos e cidades estão historicamente ligados e sua constante transformação se apresenta também na sua inter-relação de forças. A literatura acadêmica vem explorando esse tema há décadas, principalmente a partir das décadas de 70 e 80 do século passado. Existem várias interações, fases e classificações de cidades portuárias com desafios específicos relativos à sua dinâmica econômica e espacial local. No Brasil, e em especial no Maranhão, pouco tem sido pesquisado sobre esse importante tema. A cidade de São Luís representa hoje o maior complexo portuário do Brasil em volume de carga, com perspectivas de crescimento onde, ao mesmo tempo, fatores espaciais e culturais se mostram como desafios de uma nova fase nessa relação porto-cidade. O objetivo deste artigo é entender as principais fases históricas da cidade de São Luís como cidade-portuária em uma perspectiva teórica e com base nesse levantamento bibliográfico e percebido, recomendar novas linhas de novas pesquisas para o aprofundamento do tema.
\end{abstract}

Palavras-chave: Relação porto-cidade. Complexo Portuário de Baia de São Marcos. São Luís (MA). Cidade-portuária. Planejamento Urbano

Aвstract Ports and cities are historically connected, and their constant transformation also presents itself in their interrelation of forces. Academic literature has been exploring this theme for decades, especially since the 1970s and 1980s. There are several interactions, phases and classifications of port cities with specific challenges related to their local economic and spatial dynamics. In Brazil, and especially in Maranhão, little has been researched on this important topic. The city of São Luís today represents the largest port complex in Brazil in cargo volume, with growth prospects where, at the same time, spatial and cultural factors are presented as challenges of a new phase in this port-city relationship. The objective of this article is to understand the main historical phases of the city of São Luís as a port city from a theoretical perspective and based on this bibliographic and perceived survey, recommend new lines of new research to deepen the theme.

Keywords: Harbor-city relationship. Port Complex of São Marcos Bay. São Luís (MA). City-Port. Planning. 
Resumen Puertos y ciudades están históricamente ligados y su constante transformación se presenta también en su interrelación de fuerzas. La literatura académica viene explorando ese tema desde décadas, principalmente a partir de las décadas del 70 y 80 del siglo pasado. Hay varias interacciones, fases y clasificaciones de ciudades portuarias con desafíos específicos relativos a su dinámica económica y espacial local. En Brasil, y en especial en Maranhão, poco ha sido investigado sobre ese importante tema. La ciudad de São Luís representa hoy el mayor complejo portuario de Brasil en volumen de carga, con perspectivas de crecimiento donde, al mismo tiempo, factores espaciales y culturales se muestran como desafíos de una nueva fase en esa relación puerto-ciudad. El objetivo de este artículo es entender las principales fases históricas de la ciudad de São Luís como ciudad-portuaria en una perspectiva teórica y con base en ese levantamiento bibliográfico y percibido, recomendar nuevas líneas de nuevas investigaciones para la profundización del tema.

Palabras clave: Relación puerto-ciudad. Complejo Portuario de Bahía de San Marcos. San Luis (MA). Ciudad-puerto. Planificación Urbana

\section{PORTOS: ORIGEM DE MUITAS CIDADES}

Muitas cidades começaram como pontos de comércio, com o porto como interface natural entre a terra e as vias navegáveis, permitindo pequenos vilarejos litorâneos ou ribeirinhos se tornarem cidades e impulsionarem o desenvolvimento urbano, graças à prosperidade trazida pelas trocas comerciais. A observação de mapas de cidades antigas mostra as fortes interligações do porto com o desenvolvimento urbano e econômico, demonstrando, assim, a importância das cidades portuárias no nascimento e desenvolvimento da economia de mercado global, capitalista. Portos são infraestruturas de transporte conectadas à cidade. Mesmo se eles desapareceram da zona urbana, continuam a influenciar a vida econômica da cidade em sua proximidade. Essa relação tem sido forte na História e continua se mantendo nos dias de hoje.

Particularmente no caso dos portos e cidades, estudos de autores como Ferreira (1997) e Sales (1999) indicam um processo de afastamento contínuo entre cidades e portos, já a partir dos anos 1950, sempre associado à eficiência dos fluxos. Desde a década de 1950 (EUA) e décadas de 1960 e 1970 (na maioria dos países da Europa ocidental), cidades e portos apresentam processos de desorganização e redefinição de funções decorrentes, entre outros aspectos, dos avanços da engenharia naval, do aumento da capacidade dos navios e da consequente necessidade de maiores profundidades, da introdução de novos métodos e tecnologias de manuseio de cargas e também em razão da própria dinâmica de mercado. Esse movimento de afastamento espacial, percebidos nesse período, originou-se da necessidade de ganhos de produtividade na movimentação das mercadorias. Porém, tais mudanças nem sempre foram imunes aos conflitos.

No Brasil, nas últimas décadas, também foram observadas grandes transformações em várias capitais, sendo estas em sua maioria áreas metropolitanas localizadas no litoral. O crescimento urbano intenso em suas zonas portuárias, aliado à necessidade para atender navios de maior calado, levaram à saturação de diversos portos e a uma transformação nas funções por- 
tuárias de algumas cidades, transformando e forçando a relocalização de suas zonas portuárias originais para outras cidades ou áreas próximas, e produzindo como consequência, uma fase de afastamento nas relações porto-cidade, sob o aspecto espacial, econômico, logístico e cultural.

Entre os exemplos dessa mudança dessa relocalização da atividade portuária, podemos citar as transferências gradativas ou substutivas de atividades portuária:

- Do Porto de São Luís para o Porto do Itaqui (1970)

- Do Porto do Rio de Janeiro para o Porto de Sepetiba (1982)

- Do Porto do Recife para o Porto de Suape (1983)

- Do Porto de Belém para o Porto de Vila do Conde (1985)

- Do Porto de Fortaleza (Mucuripe) para o Porto do Pecém (2002)

\subsection{Elementos e conceitos na relação porto-cidade}

De acordo com Hoyle (1998), o conceito "cidade-portuária" (port city) é recorrente na história da civilização e simboliza a grande interdependência e associação entre as cidades e os portos, sendo que o tema "relação porto-cidade" foi primeiramente utilizado pelo geógrafo israelense Yehuda Hayuth no artigo The port-urban interface: an area of transition (1982), com foco na interface espacial entre o porto e a cidade.

A literatura traz ainda vários trabalhos definindo a relação porto-cidade, mas ainda inexiste uma clareza sobre a definição específica de cidade-portuária. Assim, entendemos que esse termo pode ser simplesmente compreendido como o espaço urbano localizado em litoral ou à margem de rios, provido de instalação portuária significativa. Quanto à definição de área portuária, a legislação brasileira, na Lei 12.815, traz o seguinte conceito especificamente voltado às áreas de portos públicos: “...área do porto organizado: área delimitada por ato do Poder Executivo que compreende as instalações portuárias e a infraestrutura de proteção e de acesso ao porto organizado...".

Desta forma, fica evidente que área portuária se refere aos limites formais do porto, podendo o mesmo princípio ser aplicado para o caso dos terminais privados. Já a zona portuária compreende um conceito mais amplo, sendo o resultado do aglomerado espacial compreendido pela área do porto e por seus arredores.

Rodrigue J. R., Claude Comtois e Brian Slack (2009) explicam que existe uma relação entre a extensão de área do porto e a extensão da área metropolitana em que este está localizado, especialmente nas cidades costeiras com relevantes instalações portuárias. As atividades marítimas e consequentemente portuárias sempre foram um condutor direto para o crescimento urbano. Nas últimas décadas, a conteinerização e a globalização dos mercados deram novo impulso ao crescimento urbano das cidades portuárias, favorecendo a instalação de terminais portuários muito maiores e especializados, com amplas conexões de acesso para amplas áreas de influência (hinterlândia).

Assim, as modernas cidades portuárias se tornaram pontos nodais do comércio internacional, canalizando rotas de navios, movimentos da carga e fluxos de migração, a exemplo dos 
portos do norte da Europa. Mudanças no desenvolvimento da área da cidade influenciam no crescimento na área do porto e vice-versa. Frequentemente, o crescimento rápido das áreas urbanas de apoio às atividades portuárias produzem sérios impactos na logística e nos planos de expansão do porto devido a existência de demandas concorrentes por terrenos e frentes costeiras cada vez mais escassas. Contudo, esse problema se torna ainda mais crítico em situações de crescimento desordenado e irregular em zonas portuárias, uma realidade frequente em várias cidades portuárias do Brasil. Assim, sem o planejamento espacial integrado e sensível, que considere as necessidades de ambos os lados, a eficiência do porto e a qualidade de vida das pessoas da cidade podem ser afetados.

Os conflitos passam a surgir na área litorânea quando o porto tenta expandir seus limites em uma área com demandas concorrentes ou terrenos indisponíveis. Gleave (1997) argumenta que a teoria espacial urbana parece ignorar essa possibilidade, que modelos de estrutura urbana que têm pouco a dizer sobre o papel da atividade portuária na formação da estrutura espacial das cidades. Assim, o planejamento para o desenvolvimento físico de uma cidade portuária deva ser diferente em relação ao de uma cidade convencional no continente, pois precisa reconhecer os as necessidades e os impactos do desenvolvimento portuário no crescimento da cidade.

Hoyle (1998), conforme mostra a Figura 1, afirma que a interface porto-cidade pode ser definida como a "linha de demarcação geográfica entre as terras de uso do porto e as terras de uso da cidade", sendo tais interações existentes nessa interface manifestadas por vezes de forma cooperativa, por vezes de maneira competitiva ou discordante.

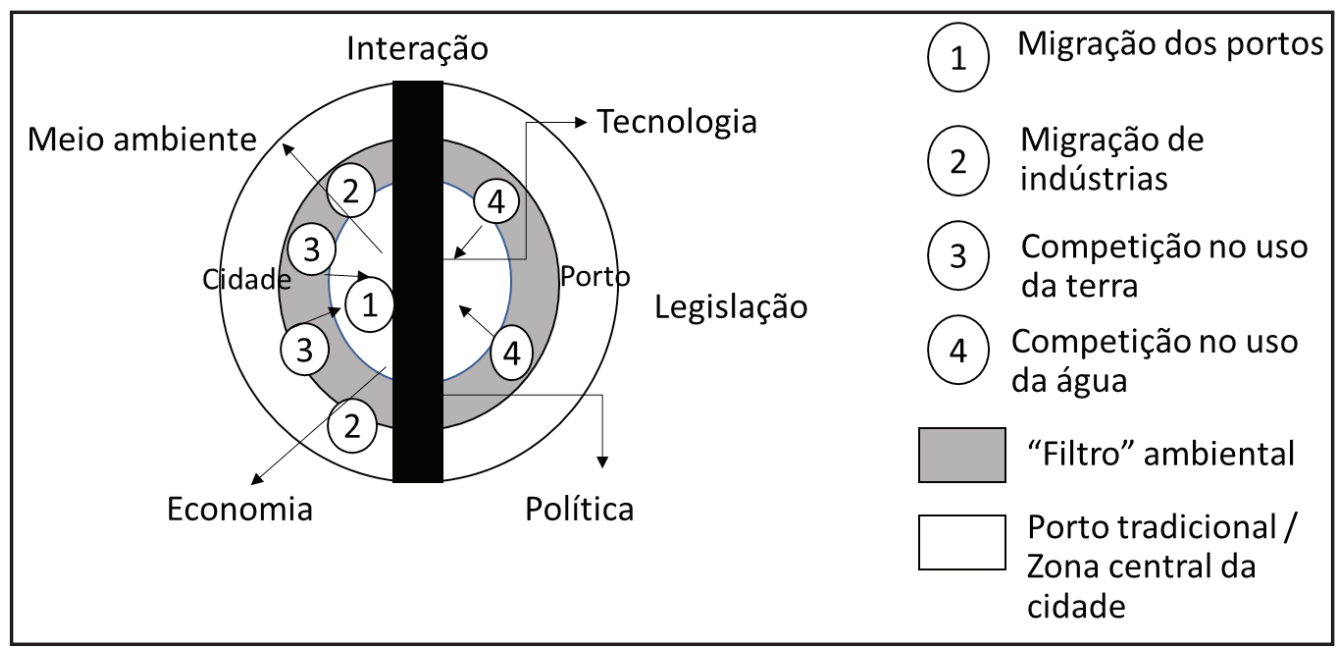

Figura 1: Fatores e processos envolvidos no desenvolvimento de cidades portuárias. Hoyle (1998)

Na relação porto-cidade, os portos podem assumir diversas funções ao longo de seu ciclo de vida. Muitos deles surgiram inicialmente por motivos ligados à expansão comercial e territorial, incluindo aqueles surgidos durante o período expansionista e de colonização europeia 
nos séculos XV a XVI. Entretanto, os portos podem ainda assumir outras funções como a função industrial, a função comercial e financeira, a função militar, além de funções secundárias voltadas ao turismo, ao lazer e aos aspectos históricos da cidade.

\section{ETAPAS DE EVOLUÇÃO DA RELAÇÃO PORTO-CIDADE}

Bird (1963) define três fases de evolução do porto: a etapa inicial de instalação a fase de expansão de armazenamento e movimentação e a etapas de instalações avançadas. Hoyle (1998), por outro lado, sugere cinco etapas de desenvolvimento da relação porto-cidade como ilustrado na Figura 2. A começar por uma primeira etapa de portos primitivos de estreita associação espacial e funcional entre a cidade e o porto (idade medieval ao século XIX), até o estágio de porto moderno de grande escala, que consome grande áreas de terra e espaço aquático (1990) na etapa cinco.

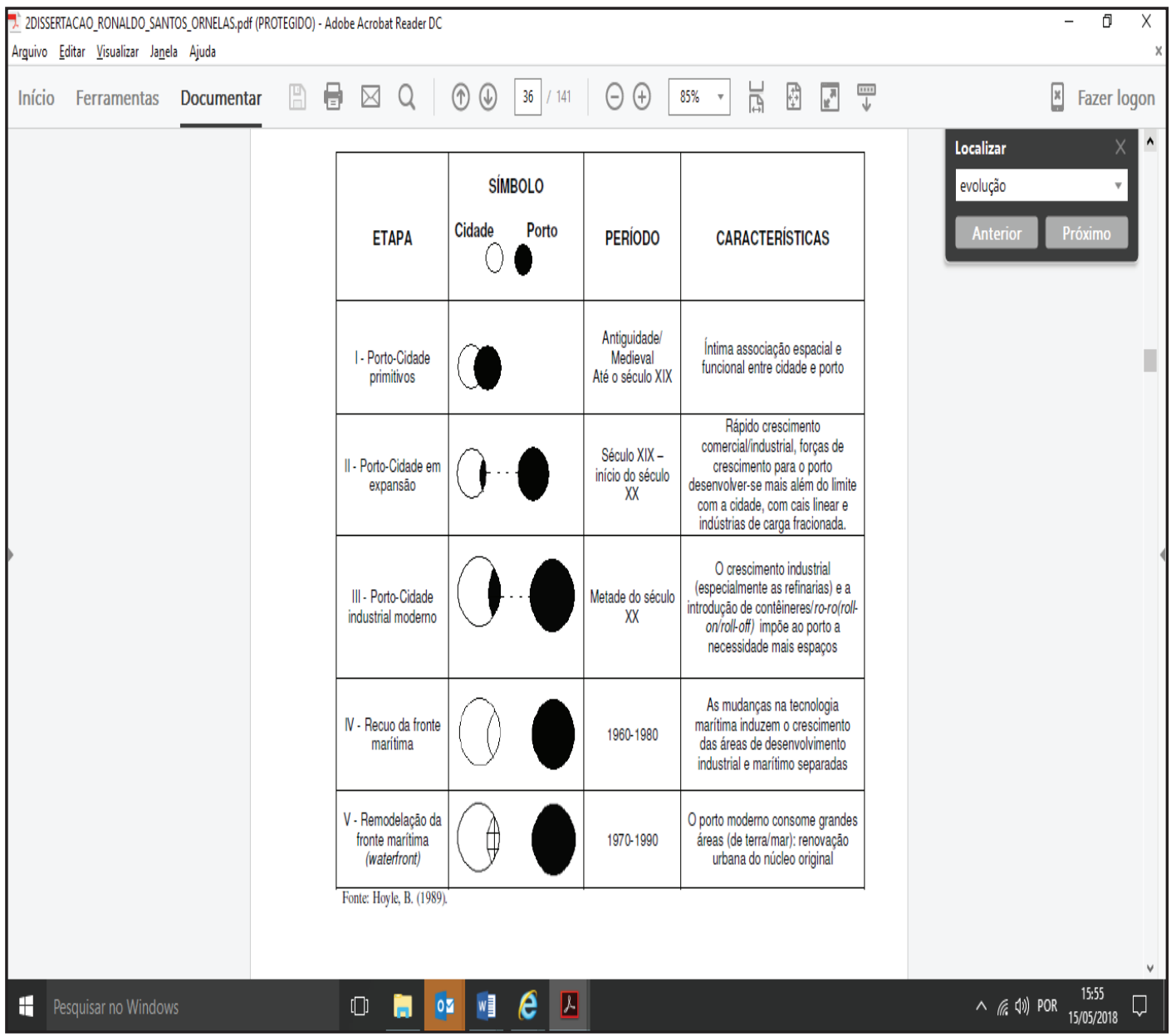

Figura 2: Etapas de evolução das relação porto-cidade Fonte: Hoyle (1998) 
Alguns pesquisadores já adicionam uma nova etapa (ou fase), dando sequência ao modelo mencionado proposto por Hoyle (1998), representando a tendência dos últimos 20 anos de integração do porto com a cidade por meio da reconversão da fronte marítima (waterfront) e dos espaços urbanos.

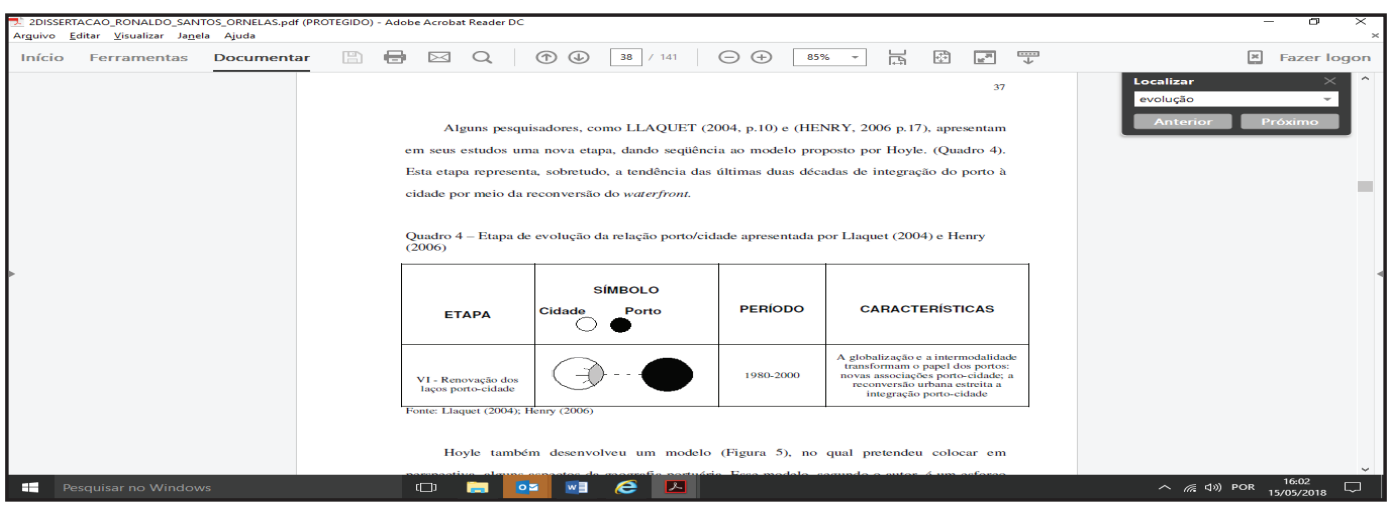

Figura 3: Nova etapa de evolução da relação porto-cidadeLlaquet (2004) e Henry (2006).

\section{EVolução portuÁRIA de SÃo LUíS}

\section{Breve histórico de São Luís}

Localizada na costa norte do Brasil, São Luís conta atualmente com aproximadamente um milhão de habitantes. A cidade de São Luís foi fundada no dia 8 de setembro de 1612, em uma ilha, que mais tarde seria a capital do Maranhão. Trata-se da única cidade brasileira fundada por franceses. Tempos depois, ela foi invadida por holandeses e, na sequência, colonizada pelos portugueses. O nome da cidade é uma homenagem dada pelos franceses ao rei da França, Luís IX, também chamado de "São Luís".

\section{A fase da Praia Grande (1612-1960)}

De acordo com Moreira Lima Neto (2005), o primeiro e mais antigo registro a respeito das atividades do Porto de São Luís, localizado na Praia Grande, veio do navegador lusitano Simão Estácio da Silveira, no livro Relação Sumária das Coisas do Maranhão (Lisboa, 1624), onde ele testemunhou ser um "porto boníssimo". Simão esteve em São Luís logo após a derrota dos franceses. Essa declaração já demonstrava ainda na época a forte vocação portuária dessa cidade.

A área da Praia Grande dominou por séculos a economia da cidade de São Luís e do Estado do Maranhão. Foi o cenário principal do maior esplendor econômico do Maranhão, entre os anos 1750 a 1820, onde a cultura algodoeira produziu a transformação de São Luís em um dos principais portos exportadores, elevando assim, suas exportações para um terço da totalidade do país. Ela continuou a ser o principal núcleo comercial importador e exportador para a economia do estado, com o Porto de São Luís sendo a base de toda comunicação e co- 
mércio. Comparando essa fase do Porto de São Luís com os modelos teóricos de Bird (1963), Hoyle (1998), encontramos semelhanças ao período de fase 1 de cidades-portuárias primitivas, caracterizadas pela íntima associação espacial e funcional entre as partes.

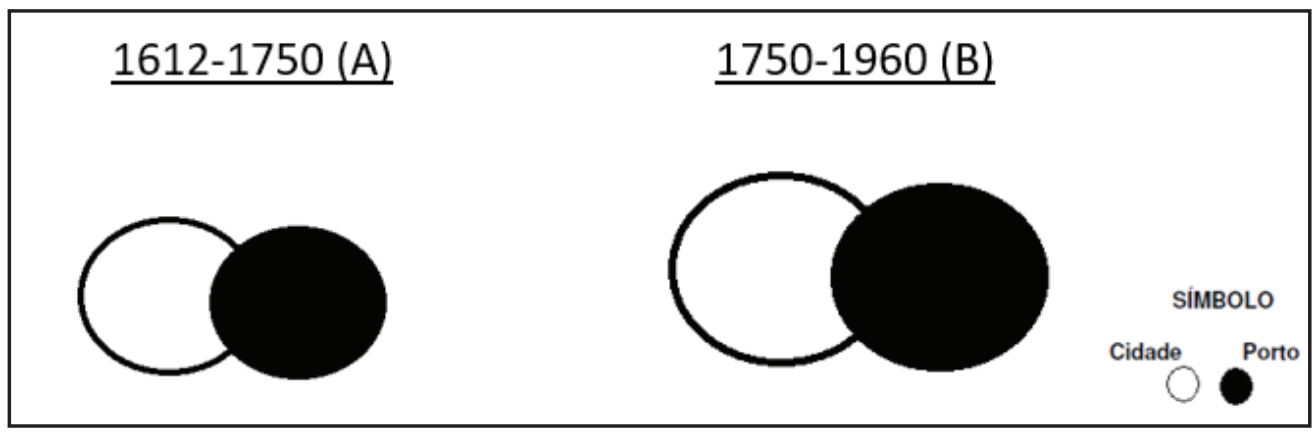

Figura 4: Representação simbólica da relação porto-cidade de São Luís durante o período do porto de São Luís na Praia Grande.

Notação:

A: Função comercial e de defesa.

B: Função comercial expandida e crescimento da cidade, ainda na mesma área geográfica.

\section{Relocalização do porto e surgimento do porto do Itaqui (1970-1980)}

No início da década 60, com o surgimento de uma nova política de transporte voltada ao desenvolvimento e interligação entre as capitais pelo modal rodoviário, dá-se início ao franco declínio da Praia Grande e do então porto de São Luís.

A partir desse momento, surgiram novos polos comerciais na cidade e finalmente o poderoso comércio da Praia Grande perdeu sua hegemonia e controle econômico no estado passando hoje a representar apenas um elemento da história econômica e portuária. Onde já foi o porto de São Luís resistem simplesmente pequenos barcos de passageiros, e onde já foram grandes armazéns no passado, hoje, centros de turismo.Com o declínio da Praia Grande, surge o Porto do Itaqui, localizado a oeste da ilha e a aproximadamente $10 \mathrm{~km}$ do centro, como a nova solução portuária. O Itaqui foi inaugurado em 1970 e iniciou oficialmente suas operações no ano 1971. Nessa fase, o desenvolvimento portuário da cidade deslocou-se para áreas mais afastadas do centro e das áreas urbanas.

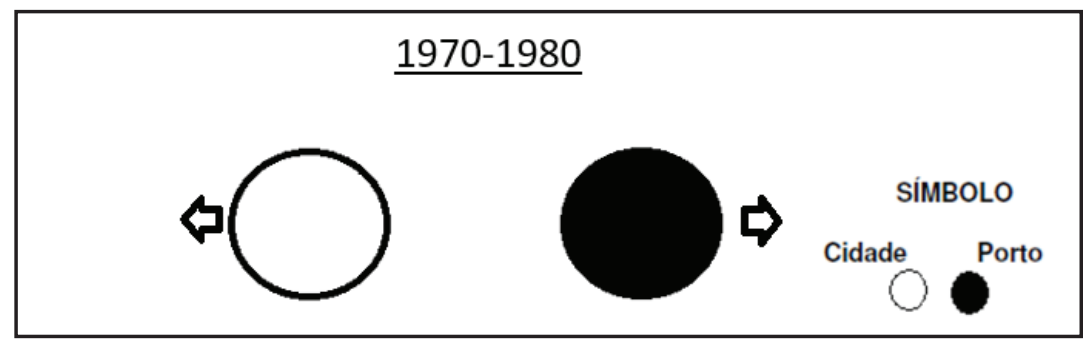

Figura 5: Porto de Itaqui: Deslocamento da área portuária da cidade. 
A figura 5 representa o afastamento espacial do porto em relação à cidade. Isso trouxe a recuperação do espaço da Praia Grande de volta para o meio urbano. Essa fase se assemelha a uma combinação das fases II (da expansão), com a fase IV (recuo da fronte marítima), e a necessidade de novas áreas dedicadas ao desenvolvimento portuário, conforme modelos teóricos de Hoyle.

\section{O grande desenvolvimento portuário de São Luís (Década de 80)}

Entre 1980 e 1984, toda a movimentação de carga do novo porto do Itaqui se resumia à importação de derivados de petróleo do sul do país e de trigo, de origem estrangeira, sendo as exportações representadas apenas por uma pequena quantidade de óleo e torta de babaçu, quase sempre para a Argentina.

Em 1981, o Consórcio Alumar, formado pela Alcoa e a Billiton, lançou a pedra fundamental de uma moderna indústria de alumina e alumínio, erguida nas vizinhanças de Pedrinhas, ao sul da ilha de São Luís, também distante do centro da cidade. Com sua produção inicialmente voltada ao mercado externo, o consórcio ainda contava com seu próprio terminal portuário privado, mas utilizava os serviços do porto do Itaqui para a movimentação de cargas. O porto da Alumar iniciou suas operações em 1983.

Já o Projeto Carajás, dimensionado para explorar as jazidas minerais descobertas na Serra de Carajás, no Pará, além de contemplar uma ferrovia de bitola larga, com $895 \mathrm{~km}$ de extensão, ligando a mina ao litoral, precisava para embarcar o minério extraído, de um moderno e profundo terminal portuário onde pudessem atracar, sem problemas, os maiores graneleiros em operação no mundo.

Em 1986, o Terminal Marítimo de Ponta da Madeira teve suas modernas e arrojadas instalações inauguradas, confirmando uma nova fase na evolução portuária de São Luís, fortemente renovada na década de 80 .

\section{O Atual Complexo Portuário da Baia de São Marcos}

O Complexo Portuário da Baia de São Marcos, em São Luís - MA, também denominado Complexo Portuário de São Luís, ou Complexo Portuário do Itaqui, ou ainda Complexo Portuário do Maranhão, é constituído por três instalações portuárias: o porto do Itaqui (porto organizado, administrado pela EMAP), pelo terminal privado da Alumar (administrado pelo consórcio da Alumar) e pelo terminal privado de Ponta da Madeira (administrado pela VALE), conforme ilustra a Figura 6. Ao mesmo tempo, dois novos projetos portuários já se encontram em curso: o Porto São Luís e o Porto de Alcântara, estes em fase de licenciamento. Outras instalações de pequeno porte, especialmente dedicadas ao transporte de passageiros e atividades de pesca, podem igualmente ser consideradas como parte desse complexo. 


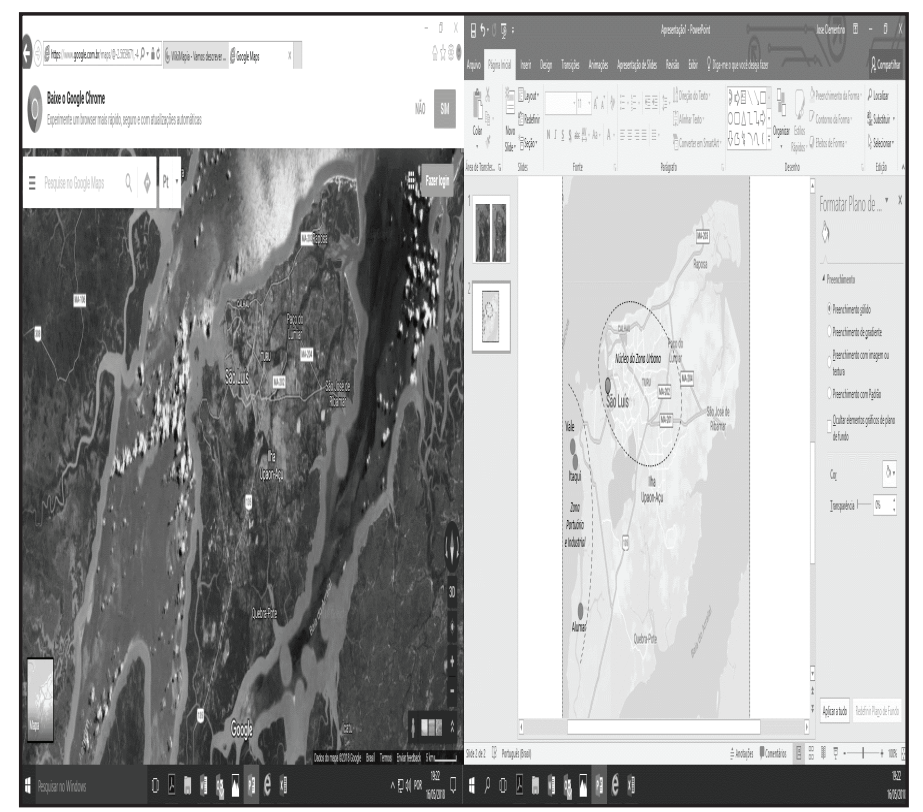

Figura 6: Mapa de São Luís, destacando a localização de suas instalações portuárias, sua zona portuária e industrial e o núcleo da sua zona urbana.

A importância do Complexo Portuário da Baia de São Marcos é indiscutível para a atividade portuária nacional. Sendo o Terminal Marítimo de Ponta da Madeira o líder em movimentação de cargas no país desde 2014. Atualmente, quase $20 \%$ do volume de carga movimentada nos portos e terminais brasileiros passam por esse complexo, e portanto, pela cidade-portuária de São Luís.

Tabela 1 - Movimentação de Carga do Complexo Portuário em mil t.

\begin{tabular}{l|l|l|l|l|l}
\hline & 2013 & 2014 & 2015 & 2016 & 2017 \\
\hline Itaqui & 15.309 & 18.029 & 21.824 & 16.898 & 19.113 \\
\hline Alumar & 12.860 & 13.684 & 14.576 & 14.160 & 14.998 \\
\hline Ponta da Madeira (Vale) & 105.700 & 112.200 & 124.600 & 148.900 & 169.800 \\
\hline Complexo Portuário da B.S. Marcos & 133.869 & 143.913 & 161.000 & 179.958 & 203.911 \\
\hline Brasil & 931.000 & 969.000 & 1.006 .000 & 998.000 & 1.086 .000 \\
\hline Percentual na mov. Nacional (\%) & 0,143791 & 0,148517 & 0,16004 & 0,180319 & 0,187763 \\
\hline
\end{tabular}

Fonte: Antaq, Anuário Estatístico.

Comparando os marcos importantes da evolução portuária de São Luís com o modelo das fases de evolução da relação porto-cidade propostos por Hoyle (1998), tendo em vista as interações espaciais e sua importância, encontramos o seguinte resultado, apresentado na Figura 7. 


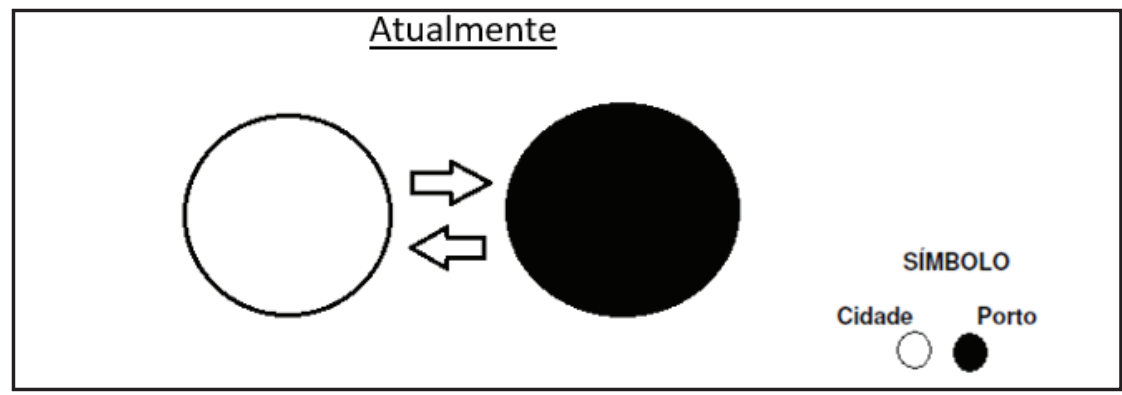

Figura 7 - Representação do movimento de reaproximação na interface porto/cidade.

Esse novo movimento de reaproximação entre o porto e a cidade pode ser evidenciado pelos seguintes elementos: Aumento populacional, ocupação industrial e não-industrial (inclusive de forma irregular) nas zonas portuárias e expansão da atividade portuária.

Apesar dos diversos planejamentos territoriais existentes na esfera municipal, estadual e federal, voltados aos portos ou à cidade, nota-se que a questão fundiária na zona portuária de São Luís ainda demanda soluções efetivas.

A degradação do distrito industrial onde estão localizados o porto do Itaqui e os terminais da Vale e da Alumar inibe expansões futuras e oferece riscos de restrições operacionais às atividades portuárias.

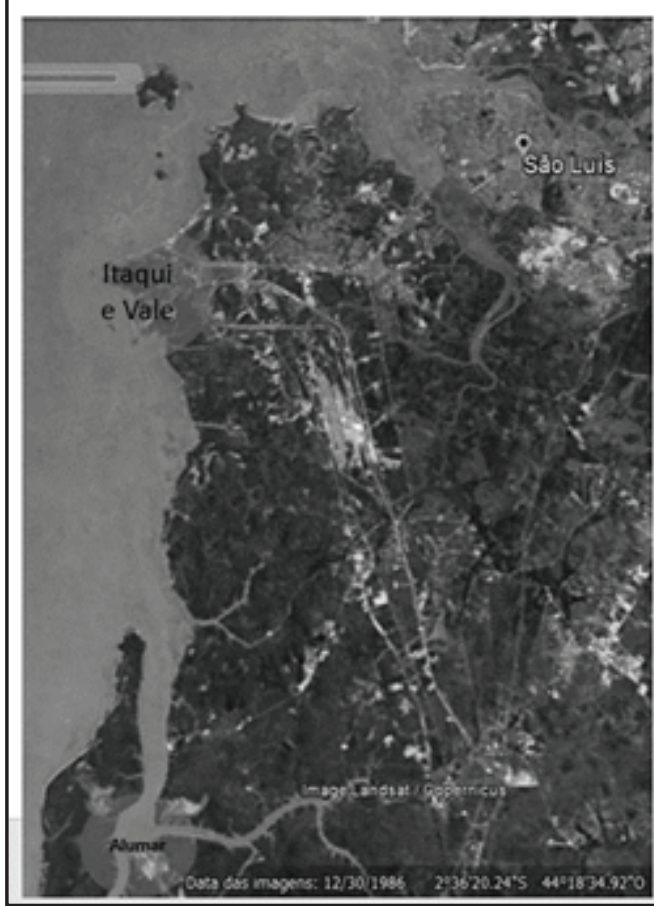

Figura 8: Foto aérea em 1986.

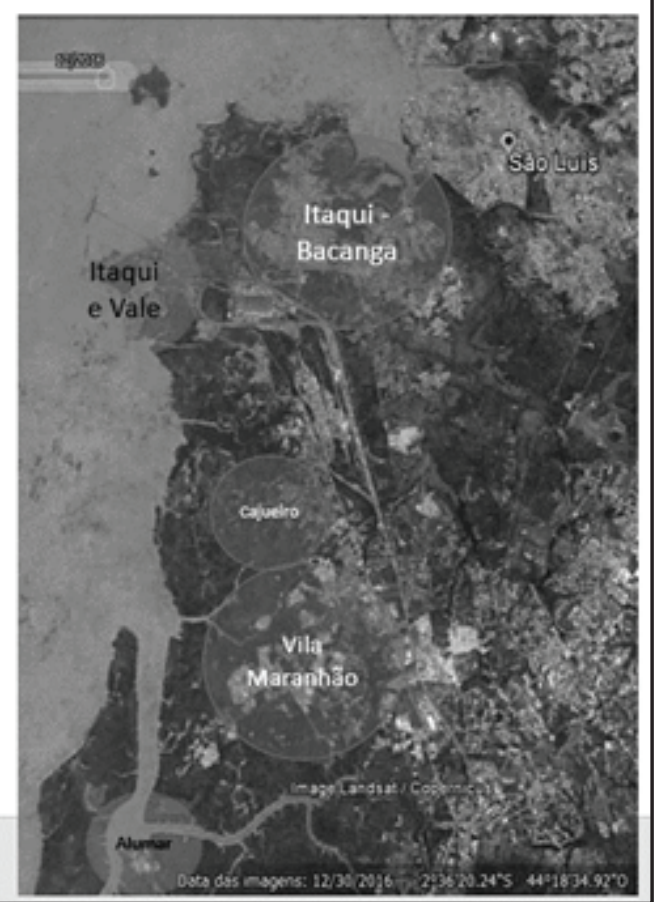

Figura 9: Foto aérea em 2016. 
Dessa forma, para um adequado desenvolvimento dos portos de São Luís e de seu Distrito Industrial, atuando como retroárea ou área de apoio na zona portuária, surge uma necessidade de um planejamento urbano mais adequado, não convencional, e que leve em conta as características distintas de uma cidade portuária, suas fases e suas perspectivas de futuro. Para tanto, existem diversas ferramentas de planejamento territorial aplicáveis:

Tabela 2 - Instrumentos de Planejamento Territorial e Portuário.

\begin{tabular}{l|l}
\hline Instrumento de planejamento & Competência \\
\hline Plano Diretor do Município & Prefeitura \\
\hline Plano Diretor do Distrito Industrial de São Luís & Gov. do Estado \\
\hline Plano Nacional de Logística Portuária - PNLP & Min. Transportes \\
\hline Plano Diretor do Porto do Itaqui & Aut. Portuária \\
\hline Plano de Desenvolvimento e Zoneamento do Itaqui & Aut. Portuária \\
\hline Revisão da Poligonal do Itaqui & Aut. Portuária \\
\hline
\end{tabular}

Não obstante esse aspecto, notam-se divergências de interpretações entre o Plano Diretor do Distrito Industrial - DISAL (Gov. do Estado) e o Plano de Uso e Ocupação do Solo (Gov. Municipal), o que também reforça a necessidade de um planejamento integrado entre os diversos planejamentos e atores.

\section{CONSIDERAÇÕES FINAIS}

Como a maioria das capitais brasileiras, e por sua própria condição de ilha oceânica, São Luís já nasceu na forma de cidade-portuária, tendo seu desenvolvimento urbano e comercial durante séculos concentrado em volta de seu porto, o porto de São Luís. A literatura que trata das diversas fases de uma cidade-portuária se reflete nas transformações da relação porto-cidade da história dessa cidade, tendo movimentos iniciais de aglutinação espacial, seguidos de movimentos de afastamento entre o porto e a cidade, logo depois de expansão e finalmente de um atual processo de reaproximação.

Sendo a cidade de São Luís o berço do maior complexo portuário do Brasil em volume de carga, o atual processo de atração mútua entre seus portos e a cidade pode e tende a se tornar ainda mais intenso com o tempo. Neste contexto, e dependendo das diretrizes tomadas por seus representantes, as relações porto-cidade poderão se moldar para vias de cooperação e complementariedade ou para vias de concorrência e conflitos por espaço em terra ou pela fronte marítima.

Para tanto, a questão do planejamento espacial das áreas urbanas e portuárias, em meio às diversas ferramentas de planejamento, torna-se um processo vital para o futuro de uma boa relação porto-cidade em São Luís, para a longevidade e competitividade de seus portos, a fim de maximizar sinergias e impactos positivos, exemplo: o porto gerando benefícios para a cidade, oportunidade de trabalho e de qualidade de vida para sua população e a cidade atraindo 
ou produzindo competitividade ao seu porto, através de serviços prestados, mão-de-obra qualificada e logística de acesso adequada, evitando assim, casos conflitantes, a exemplo do porto de Santos, do porto de Tubarão e de tantos outros no país.Como assuntos alvo para pesquisas futuras sugere-se novos modelos de planejamento dedicados para cidades portuárias, além do emprego de tecnologias e formas de planejamento territorial integrado para zonas portuárias.

\section{REFERÊNCIAS}

ABDULLAH et al. (2012). Port City Development and Quality of Life in Pasir Gudang Port, Johor, Malaysia.

ANTAQ. Agência Nacional de Transportes Aquaviários (2017). Anuário Estatístico Aquaviário.

EMAP (2012). PDZ - Plano de Desenvolvimento e Zoneamento do Porto do Itaqui, 2. ed.

HOYLE, B. S. (1998). Cities and ports: concepts and issues. Journal of Vegueta (3), 263-278.

LIMA, B. M. (2005). História do Porto do Itaqui.

OCDE (2014). The Competitiveness of Global Port-Cities: Synthesis Report. Edited by Olaf Merk.

Submetido em: 4-9-2018

Aceito em: 22-11-2018 